\title{
Treatment of hemolymphangioma of the spleen by laparoscopic partial splenectomy: a case report
}

\author{
Yue Zhang, Xue-Min Chen*, Dong-Lin Sun and Chun Yang
}

\begin{abstract}
Hemolymphangioma is a malformation of both lymphatic and blood vessels. The incidence of splenic hemolymphangioma is extremely rare. Laparoscopic partial splenectomy is feasible, reproducible, and safe in children with focal splenic tumors. We report on the case of a 12-year-old male with a large splenic hemolymphangioma successfully managed by laparoscopic partial splenectomy. The patient recovered well after operation. Laparoscopic partial splenectomy is a safe and minimally invasive technique for treatment of splenic hemolymphangioma located in the pole of the spleen.
\end{abstract}

\section{Background}

Focal splenic tumors, including splenic cysts and vascular neoplasms, are uncommon and require complete resection to prevent complications or recurrence [1]. Hemolymphangioma is a malformation of both lymphatic and blood vessels. The incidence of splenic hemolymphangioma is extremely rare. In the past, total splenectomy has been the method of choice for the treatment of splenic tumors. Today, a spleen-preserving minimally invasive approach is being increasingly advocated, especially in children and young adults, in order to avoid overwhelming post-splenectomy infection $[2,3]$. With a better understanding of vascular anatomy and the development of fine laparoscopic skills, laparoscopic partial splenectomy became safe and feasible. In this paper, we report on a rare case of splenic hemolymphangioma successfully managed by laparoscopic partial splenectomy.

\section{Case presentation}

A 12-year-old male was admitted to our hospital with a complaint of abdominal pain for one month. There was no history of trauma, no weight loss, and no family history of cancer. A physical examination showed a tender left upper-quadrant abdominal mass. Laboratory tests, including serum tumor markers, were normal. Computed tomography confirmed a large $15.7 \times 8.5 \mathrm{~cm}$ cyst

\footnotetext{
* Correspondence: tomuer@126.com

Department of Hepatobiliary Surgery, The Third Affiliated Hospital of Soochow University, Changzhou 213003, China
}

occupying the upper pole of the spleen (Figure 1) and demonstrated almost total displacement of the remaining splenic parenchyma (Figure 2).

The patient underwent a laparoscopic partial splenectomy. In brief, the patient was induced under general anesthesia and placed in the supine position. Using Hasson's technique, the pneumoperitoneum was achieved at a pressure of $8 \mathrm{mmHg}$ and a flow rate of $1.5 \mathrm{~L} / \mathrm{min}$. A $10-\mathrm{mm}$ port was placed sub-umbilically for laparoscopy. Four more ports were placed under vision: a 5-mm port in the subcostal border in the right mid-clavicular line, a $5-\mathrm{mm}$ port under the costal border $6 \mathrm{~cm}$ in the right mid-clavicular line, a $5-\mathrm{mm}$ port parallel to the umbilicus in the left anterior axillary line, and a $5-\mathrm{mm}$ port parallel to the umbilicus in the left mid-clavicular line. A hilar dissection was carefully performed, and the superior lobar vessels going toward the superior pole and cyst were identified and dissected. The vessels were clipped, which resulted in a well-defined line of demarcation at the upper pole (Figure 3). The cyst was punctured with the needle and about $800 \mathrm{~mL}$ of clear fluid was aspirated. After the cyst was evacuated and opened, using an UltraCision Harmonic Scalpel ${ }^{\circ}$ (Ethicon EndoSurgery Inc., USA), the upper pole of the spleen, along with the cyst, was resected keeping a $5-\mathrm{mm}$ rim of devascularized splenic tissue (Figure 4). A suction drain was introduced through the anterior axillary line port and positioned lateral to the upper pole of the spleen. Intraoperative blood loss was $80 \mathrm{~mL}$, and the operating time was 105 minutes. 


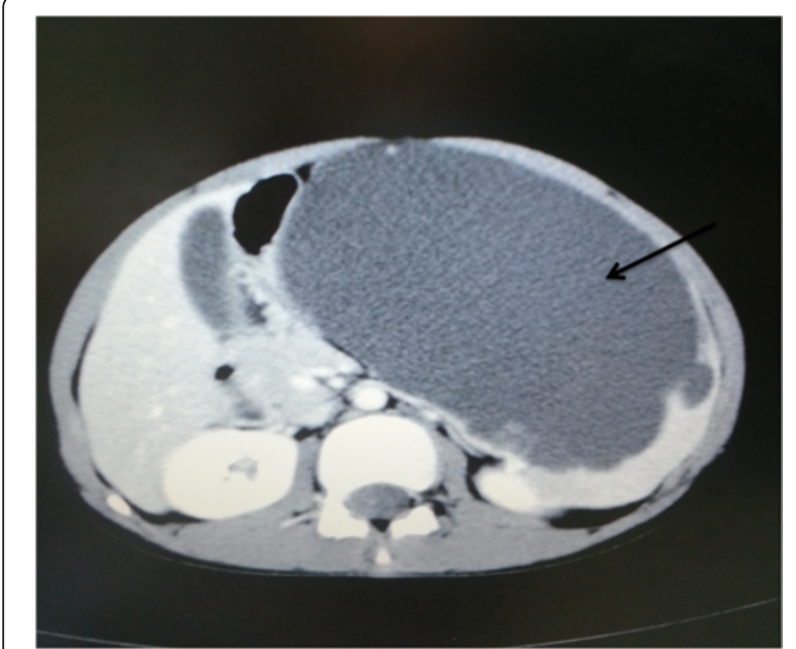

Figure 1 Computed tomography scans suggestive of a hypodense cystic lesion arising from the spleen.

No post-splenectomy infectious complications occurred. His postoperative course was uneventful. The patient is asymptomatic on a follow-up of 1 year with no recurrence on ultrasonography and a normal platelet count. Microscopically, some dysplastic lymphatic vessels and blood vessels were observed in the tumor. The pathological diagnosis was hemolymphangioma (Figure 5).

\section{Discussion}

Hemolymphangioma is a congenital malformation of the vascular system [4]. The formation of this tumor may be explained by obstruction of the venolymphatic communication between dysembryoplastic vascular tissue and systemic circulation; only one case has been

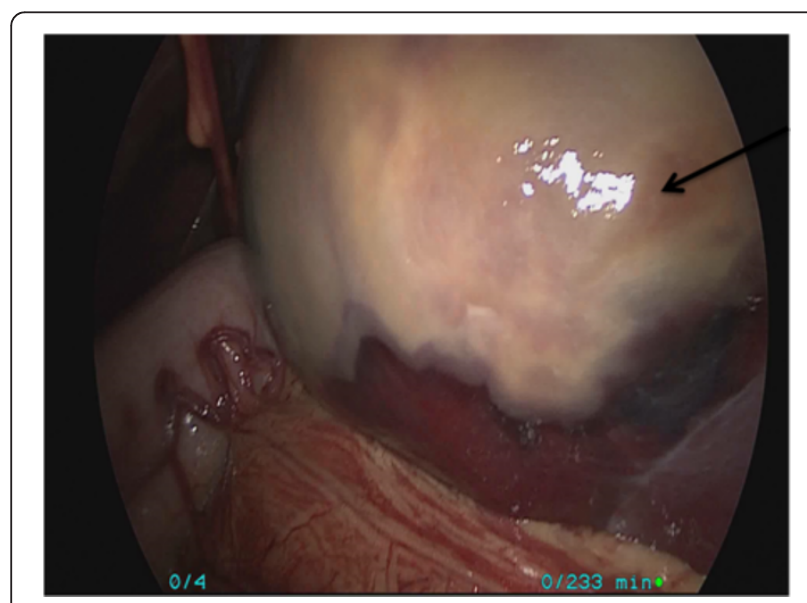

Figure 2 Splenic hemolymphangioma.

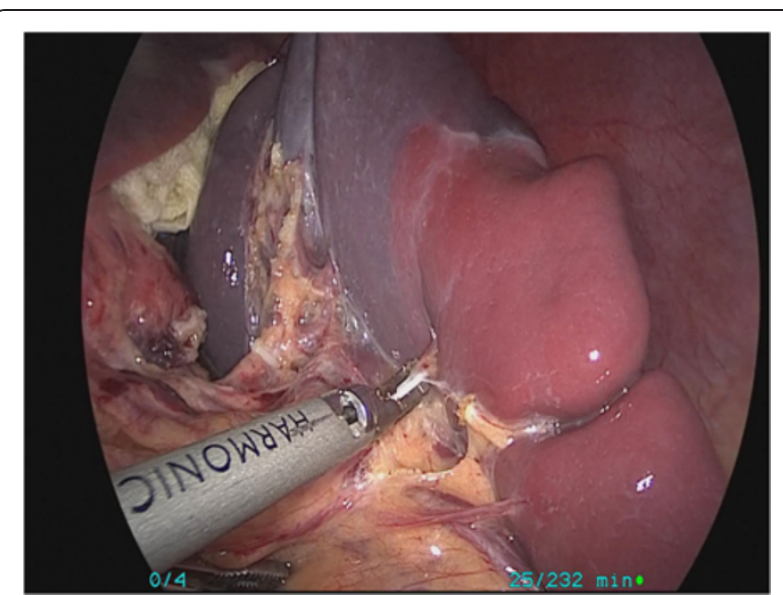

Figure $3 \mathrm{~A}$ well-defined line of demarcation at the upper pole after vessels were clipped.

reported previously [5]. Although rare, splenic hemolymphangioma should be considered in the differential diagnosis when a cystic tumor of the spleen is found, particularly when there is insufficient evidence to diagnose cystic hemangiomas, cystic lymphangiomas, and epidermoid and dermoid cysts. The optimal treatment strategy remains controversial. The surgical options are based on the size of the tumor, its relation to the splenic hilar vessels and parenchyma, and the amount of healthy splenic tissue remaining. The aim of treatment is to remove the entire tumor, sparing splenic tissue and avoiding recurrence. In a multicenter study performed in four European countries [6], a high recurrence rate was associated with laparoscopic fenestration and deroofing, and laparoscopic total cyst removal with or without splenic tissue has been considered as the

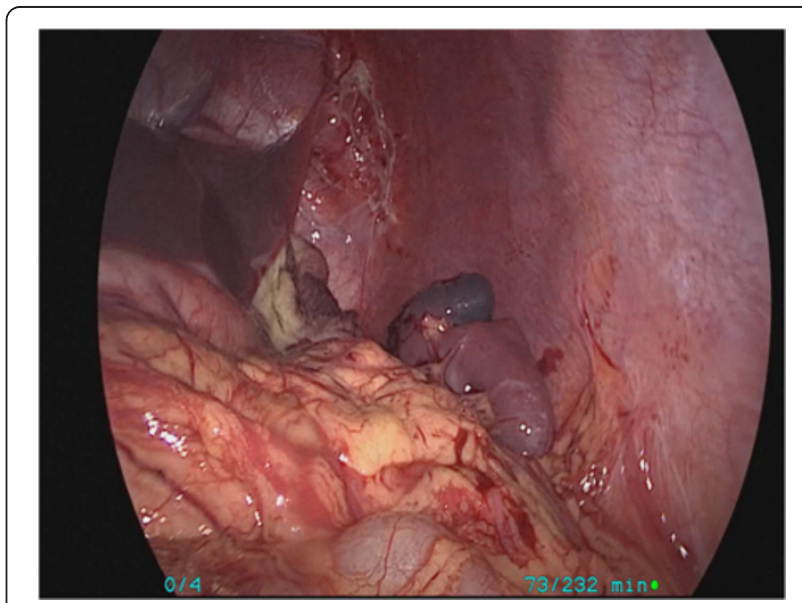

Figure 4 Complete excision of splenic hemolymphangioma. 


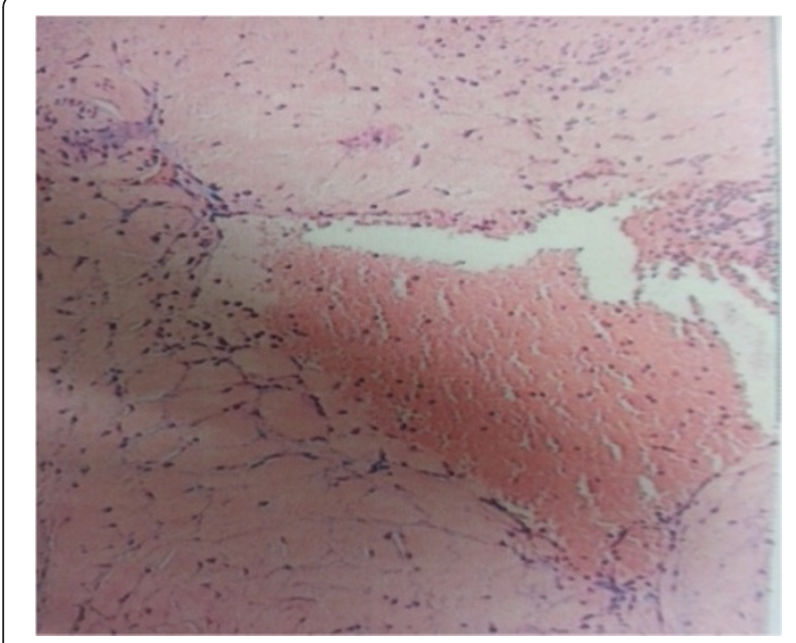

Figure 5 Pathological examination of the splenic hemolymphangioma (HE staining, 100X). treatment of choice. Additionally, deroofing carries the risk of content spillage. Currently, laparoscopic partial splenectomy is feasible, reproducible, and safe in children with hematological diseases or focal splenic tumors. Partial splenectomy is the best method to prevent post-splenectomy infections since it preserves the spleen's immune role. Laparoscopic partial splenectomy also offers the benefits of a minimally invasive approach: laparoscopy is now considered the gold standard for total splenectomy in children [7-9]. In fact, laparoscopy leads to fewer complications such as wound dehiscence, infections, intussusceptions, and pleural effusions. Less postoperative adhesion facilitates a second laparoscopy if completions of the splenectomy or cholecystectomy are required. According to Minkes [10], laparoscopic splenectomy in children can be performed safely with a low conversion rate (2.9\%). Laparoscopic partial splenectomy is still a challenging procedure (e.g., bleeding from the cut edge of the spleen can be difficult to control). Nevertheless, with an understanding of the vascular anatomy of the spleen, it can be safely performed. Based on vascular distribution, the spleen is divided mainly into two lobes. In our case, when the upper lobe vessels were ligated, the line of demarcation was formed making it easily accessible for partial splenectomy without major blood loss.

\section{Conclusions}

In conclusion, laparoscopic partial splenectomy is a safe and minimally invasive technique for the treatment of splenic hemolymphangioma located at the pole of the spleen.

\section{Consent}

Written informed consent was obtained from the patient's parents for the publication of this report and any accompanying images.

\section{Competing interests}

The authors declare that they have no competing interests.

\section{Authors' contributions}

$Y Z$ and $X-M C$ drafted and revised the manuscript. D-LS and $Y C$ were responsible for acquisition and interpretation of data. All authors read and approved the final manuscript.

\section{Acknowledgements}

The authors thank Sheng yong Liu for language editing.

Received: 28 August 2013 Accepted: 14 March 2014

Published: 21 March 2014

\section{References}

1. Willcox TM, Speer RW, Schlinkert RT, Sarr MG: Hemangioma of the spleen: presentation, diagnosis and management. J Gastrointest Surg 2000, 4:611-613.

2. Dan D, Bascombe N, Harnanan D, Hariharan S, Naraynsingh V: Laparoscopic management of a massive splenic cyst. Asian J Surg 2010, 33:103-106.

3. Jain P, Parelkar S, Shah H, Sanghvi B: Laparoscopic partial splenectomy for splenic epidermoid cyst. J Laparoendosc Adv Surg Tech A 2008, 18:899-902.

4. Balderramo DC, Di Tada C, de Ditter AB, Mondino JC: Hemolymphangioma of the pancreas: case report and review of the literature. Pancreas 2003, 27:197-199.

5. Scaltriti F, Manenti A: Hemolymphangioma of the lower pole of the spleen (migrated into the pelvis minor). Chir Ital 1967, 19:543-554.

6. Czaundera P, Vajda P, Schaarschmidt K, Kalman A: Nonparasitic splenic cysts in children: a multicenteric study. Eur J Pediatr Surg 2004, 16:415-419.

7. Rescorla FJ, Engum SA, West KW, Tres Scherer LR 3rd, Rouse TM, Grosfeld JL: Laparoscopic splenectomy has become the gold standard in children. Am Surg 2002, 68:297-301. Discussion 301-302.

8. Hery G, Becmeur F, Mefat L, Kalfa D, Lutz P, Lutz L, Guys JM, de Lagausie P: Laparoscopic partial splenectomy: indications and results of a multicenter retrospective study. Surg Endosc 2008, 22:45-49.

9. Geraghty M, Khan IZ, Conlon KC: Large primary splenic cyst: a laparoscopic technique. J Minim Access Surg 2009, 5:14-16.

10. Minkes RK, Lagzdins M, Langer JC: Laparoscopic versus open splenectomy in children. J Pediatr Surg 2000, 35:699-701.

\section{doi:10.1186/1477-7819-12-60}

Cite this article as: Zhang et al:: Treatment of hemolymphangioma of the spleen by laparoscopic partial splenectomy: a case report. World Journal of Surgical Oncology 2014 12:60.

\section{Submit your next manuscript to BioMed Central and take full advantage of:}

- Convenient online submission

- Thorough peer review

- No space constraints or color figure charges

- Immediate publication on acceptance

- Inclusion in PubMed, CAS, Scopus and Google Scholar

- Research which is freely available for redistribution 